\title{
DETERMINANT OF ADULT EDUCATION PROGRAM: A CRITICAL ANALYSIS OF ADULT EDUCATION IN SOME SELECTED TRAINING CENTERS OF EASTERN REGIONS
}

\author{
Yilfashewa Seyoum $^{1}$; Yonas Amdemeskel ${ }^{2}$ \\ ${ }^{1}$ Department of Adult Education and Community Development, College of Education, Ethiopia \\ ${ }^{2}$ Department of Behavioral Sciences, Haramaya University, Ethiopia \\ 1yilfa2014@gmail.com
}

\begin{abstract}
The purpose of this study was to analyze the factors affecting adult education in the eastern part of Ethiopia. The study employed a survey design that involved qualitative and quantitative approaches. A stratified random sampling technique was used to select 515 male and 285 female respondents. A questionnaire and an interview for collecting information from the primary sources were designed and implemented. Data were analyzed with linear correlation and Ordinary Least Square (OLS) regression. The findings indicated that the relationship of overall adult learning achievement to assessment of learning $(r=0,29, P<0,01)$, and the methods used by facilitators $(r=0,23, P<0,01)$ is positive and significant. The regression model demonstrated that overall adult learning condition is significantly affected by variables such as relevance of the content, methods of teaching, assessment of learning outcome, and locality of the adult education learners.
\end{abstract}

Keywords: adult education program, training centers, Curriculum relevance

\section{INTRODUCTION}

Education played big role as a major driver of economic competitiveness in an increasingly knowledge-driven global economy. Contemporary society has high expectations of the contribution that education can make in helping people learn to live with change, to lead change, and to support improvement in all spheres of life (Kala \& Chaubey, 2015). Education is a prerequisite for short and long-term economic growth. As a result, no country has achieved continuous and rapid economic growth without at least 40 percent of adults being able to read and write (Merriam \& Cunningham, 2007). The formal system, which is elitist, discriminatory and installment, cannot alone help man to attain all education he needs for achievement of self-fulfillment and national development. Terminologies, such as, adult education, continuing education, recurrent education, education permanent, and lifelong education, have been used by different bodies to stress that education is a very useful tool to our life (Torres, 2006).

Kanukisya (2008) noted that the term 'adult education' is used with at least three different meanings. In its broadest sense, it describes the entire process of adults learning. In its more technical meaning, 'adult education' describes a set of organized activities to a wide variety of institutions for the accomplishment of specific educational objectives. The third meaning combines all of these processes and activities into the idea of a movement or field of social practice. In this sense, 'adult education' brings together into a discrete social system all the individuals, institutions, and associations concerned with the education of adults and perceives them as working toward common goals of improving the methods and materials of adult learning, extending the opportunities for adults to learn, and advancing the general level of life (Nafukho, et al., 2011). 
The document compiled by UNESCO (2010) argues that literate, numerate, and problemsolving workers who can add value to the production of goods and services at every possible point are needed. In order to improve learner participation in developmental programs, learning opportunities must be created by making education accessible to all. The introduction of adult and lifelong learning in the workplace is the first step to personal, educational and skills development. Tight (1996) contended that promotion at work often depends on an individual's ability to read and write local and international language in order to read job cards, write reports, follow written directions and instructions. Sabo et al., (2006) concurred with the former by recognizing that adult learning would be a key issue in the twenty-first century and stress its importance for sustainable development, promoting democracy, justice, gender equity and other aspects of development, and ultimately for building a better and more peaceful society.

Among the characteristic features of adults, mental maturity and social responsibility are included. It is through adult education that adults are helped to mentally articulate to understand issues and judge rightly, and are able to perceive reality in order to creditably discharge their social roles as parents and leaders. For instance, mothers have to know the new responsibilities placed on them over the family from time to time. Also, fathers should be made to understand their roles at any point in time as the changing socio-economic realities of their countries. Nowadays, there have been programs organized for nursing mothers to intimate them with the need for breast-feeding, family planning and new approach to child-rearing (Tilak, 2006). The series of outreach programs organized by different institutions through different strategies is to bring to the knowledge of adults, men and women, the problems and solutions to different diseases, such as cholera, tapeworm and hepatitis (UNESCO, 2007). Thus, one could assert that the whole society has constituted training through which adults continuously learn and attain fullness in all its ramifications. That is, in every section of the society, different and necessary education programs are continuously offered to adults. This results in improved quality of life of which modern society is blessed with (Nafukho, et al., 2011).

In Ethiopia, as a result of the implementation of successive education sector development programs, access to formal schooling has significantly grown from its previous low level. However, in 2008, the Ministry of Education clearly disclosed the fact that the status of adult education in Ethiopia remained low in terms of both accessibility and relevance. Adult education programs implemented so far had not been geared towards problem-solving and was not relevant to the day-to-day life of the adult population (Ministry of Education, 2008a). Adult education plays both complementary and supplementary roles in education in a country. Consequently, Ethiopia should heighten efforts in adult education so as to afford citizens opportunities to attain self-fulfillment and national development in the twenty-first century.

In order to alleviate the adult education problems, as how Education Sector Development Program III (Ministry of Education, 2005) put it that life skill-based, work-oriented and communitybased adult education programs must be scaled up. The attention to adult education is to convey essential knowledge and skills among adults and to facilitate conditions for the provision of Functional Adult Literacy (FAL) programs. In addition, it is designed to create milieu to adults to read and write in order to acquire knowledge and skills in agriculture, health, civic education, cultural education, etc. To this end, the strategy for adult education was developed with the active participation of all stakeholders in 2008. Nevertheless, the current adult education program has facedenormous problems accumulated through years. The strategic document uncovered the reality that the number of adult illiterates has remained high, and the issue has become the major challenge and priority area in the sector (Ministry of Education, 2005; Ministry of Education, 2008b).

ESDP IV also foresees a major program in Ethiopian adult education program (the objective of which is to allow all adult illiterates to participate in two years of Functional Adult Literacy (FAL) courses. The emphasis has been shifted towards FAL to ensure active participation of the literate population in the socio-economic development of the nation. A Master Plan for Adult Education has 
been drafted. It is expected to devote efforts in this sub-sector during ESDP IV implementation (Ministry of Education, 2010).

The purpose of this research was, therefore, to analyze those factors to debilitate or facilitate the existing adult education program. In a more explicit manner, an attempt wasmade to identify the variables that most likely determine the success of adult education program in the Eastern part of Ethiopia. Moreover, effort was also made to examine the relationships between or among variables that determine the learners' success in the existing adult education deliberation.

This research is rooted from several research questions namely: (1) Which variables are significantly associated to the success of learners in the existing adult education programs? (2) What aspects of the program do adult learners experience as a challenge? (3) Which barriers are accountable to affect learners'achievement in the current adult education program?

\section{METHODS}

The main objective of this research was to solicit the factors that best contribute towards the attainment of adult learning program in the Western and Eastern Hararghe, Dire Dawa, Harar and Jigjiga town of Somali region. In order to attain this general objective, the study employed a survey design that involves qualitative and quantitative research approaches (mixed research design). According to Best and Khan (2005), survey involves acquiring information about one or more group of people, asking them questions and tabulating their answers. The ultimate goal of a survey research design is to learn about a large population by surveying their representative sample, summarizing their responses in percentages, frequency, as well as with more sophisticated statistical methods (Sarantakos, 2005). Survey helps to identify the major practice, opinions, suggestions and comments pertaining to the issue under study.

In order to address the fulfillments of a survey design, both primary and secondary sources of data were used to collect the required information. The primary data were collected from adult learners and adult education coordinators. Moreover, the study encompasses secondary data sources like National Adult Education Strategy (Ministry of Education, 2008b), Integrated Functional Adult Literacy Curriculum Framework (Ministry of Education, 2011a), Functional Adult Literacy Implementation Guideline (Ministry of Education, 2011b), and National Report on the Development and State of the Art of Adult Education Program (Ministry of Education, 2008a). Likewise, reports, research articles, education statistics and important plans produced by Regional Education Bureau and Woreda Education Offices and other adult education agents were also scrutinized.

The populations of this research were adult learners found in Harar, Dire Dawa, Eastern and Western Hararghe Zones and Jigjiga Town (all are in the Eastern part of Ethiopia). Overall, about 800 research participants were included. A stratified random sampling technique was used to select the sample learners of which 515 male and 285 female respondents. For the purpose of interview, about 20 respondents were also considered.

A questionnaire was employed as a major tool to collect information from the primary sources of the data. The questionnaire has two parts in which the first part of it aimed at obtaining biographical information about respondents. The second part designed to secure information about the actual practices of adult learning programs. In order to assure the truthfulness and internal consistency of the tool, a pilot test was conducted. Accordingly, the following result was obtained, as seen in Table 1. 
Table 1 Reliability Statistics

\begin{tabular}{lcc}
\hline Category of items & Number of items & Cronbach's Alpha \\
\hline Items related to relevance of adult education program & 10 & 0,88 \\
Items related to teaching - learning process & 10 & 0,92 \\
Items related to assessment of learning outcome & 11 & 0,98 \\
Overall & 31 & 0,906 \\
\hline
\end{tabular}

The Crombach Alpha reliability coefficient of tryout test result indicates that the questionnaire has a reliability coefficient of 0,88, 0,92 and 0,98 with overall coefficient of 0,91. Based upon Gay and Air asian criteria for accepting a research tool, the reliability coefficient should attain greater or equal to 0,7 (Gay \& Airasian, 2003). Hence, the above list of coefficients of reliability was accepted. Moreover, through face validity the items used in the questionnaire were also checked. This helped to improve the quality and credibility of the instruments. Based on the comments given, the sequence and problems of items were rectified and restructured to make the questionnaires clear and ready for the final use. Moreover, to prevent test contamination, participants who had taken part in the pilot test were purposely excluded from the study.The questionnaire was distributed for about 800 respondents (through educational supervisors and teachers' development process owners and experts).

In addition to the questionnaire, interview was also considered as a mean for securing important data. To get detail information, 10 items of semi-structured interview were designed to 8 Woreda Education Office experts and 12 facilitators. The main purpose of the interviews was to obtain detail information about the practices of adult education program. This procedure helped the researchers to triangulate and strengthen the information obtained through the questionnaire. In this regard, facilitators, coordinators and experts were asked to offer additional verbal information on the top of the review of documents about the current practices of adult education.

After collecting the necessary information, the data was edited and reduced at first and then tallied, tabulated and processed separately for each item in a way to seek appropriate answer to the basic research questions. Both quantitative and qualitative data analysis methods were used. The data collected through close-ended questionnaire were analyzed quantitatively while the data secured through interview and document analysis were reiterated qualitatively. For the quantitative data, the analysis was made using SPSS software (version 20). More importantly, correlation and regression analysis were used to deliberate quantitative methods of data analysis. On the other hand, the qualitative data analysis was analyzed through thematic description and word narration.

Also, as a part of this investigation, essential ethical principles were followed to ensure that the participants of the study were treated with respect and consideration. Before proceeding with data collection and analysis, approval was sought from the Office of the Vice-President for Research Affairs. Moreover, permission was obtained from the administrative personnel Woreda Education Offices. The participants were informed of the nature and procedures of the study. They were informed that their participation was voluntary and they had the right to withdraw from the study at any time. Every effort was made to ensure the confidentiality and anonymity of the participants, including removal of names and details from quotes and descriptions that might reveal the identity of an individual. After the completion of the interviews, participants were given opportunity to review their responses and to make any changes to their statements. 


\section{RESULTS AND DISCUSSIONS}

Inter-correlation among the various dimensions of adult learning (Content Relevance, Methods of Teaching, Overall outcome of AE, Assessment of Learning, Sex, Age, Marital Status, and Locality) were examined in order to discern the relationship between independent variables (Content Relevance, Methods of Teaching, Overall outcome of AE, Assessment of Learning, Sex, Age, Marital status, and Locality) with dependent variable (overall adult education learning). Determination of relationship between dependent variable and independent variables was found important in order to deal with further regression analysis. Table 2 presents the outcome of correlation among the respondents' variables.

Table 2 Correlation Matrix of Adult Education Variables

\begin{tabular}{|c|c|c|c|c|c|c|c|c|}
\hline & 1 & 2 & 3 & 4 & 5 & 6 & 7 & 8 \\
\hline Content Relevance & 1 & & & & & & & \\
\hline Methods of Teaching & $-0,037$ & 1 & & & & & & \\
\hline Overall outcome of AE & $0,118^{* *}$ & $0,212^{* *}$ & 1 & & & & & \\
\hline Assessment of learning & $-0,510^{* *}$ & $-0,287^{* *}$ & $0,193^{* *}$ & 1 & & & & \\
\hline Sex & $0,112^{* *}$ & $-0,070$ & $-0,014$ & $-0,117^{* *}$ & 1 & & & \\
\hline Age & $0,183^{* *}$ & $-0,357^{* *}$ & $-0,049$ & $-0,024$ & 0,017 & 1 & & \\
\hline Marital status & $0,400^{* *}$ & $-0,107^{*}$ & 0,069 & $-0,163^{* *}$ & $0,094^{*}$ & $0,278^{* *}$ & 1 & \\
\hline Locality & 0,043 & $-0,113^{*}$ & $0,119^{* *}$ & 0,055 & 0,000 & 0,074 & $0,115^{* *}$ & 1 \\
\hline
\end{tabular}

**. Correlation is significant at the 0.01 level *. Correlation is significant at the 0.05 level.

As indicated in Table 2, the interrelationships of most variables considered were significant. Specifically, the relationship of overall outcome to content relevance $(r=0,12, P<0,01)$, to methods of teaching $(r=0,21, P<0,01)$, assessment of learning $(r=0,19, P<0,01)$, locality $(r=0,12, P<$ 0,01 ) were positive and significant. Overall, the independent variables (content relevance, locality of the adult learners, methods and assessment of learning process) were significantly correlated to the dependent variable (overall outcome of adult learning) at 0,01 and 0,05 levels of significance. Hence, it was found important to extend the regression analysis to examine the effect of independent variables on the dependent variable.

Ordinary Least Square (OLS) regression was employed to provide information about the model as a whole, and the relative contribution of each of the variables that make up the model. OLS is much more appropriate when the dependent variable is measured in an interval and continuous scale. To this effect, in order to identify the variable(s) that affect to the overall achievement of adult learning, the regression model with variables, content relevance, methods of teaching, assessment of learning, sex, age, marital status, and locality were examined (See below in Table 3 \& 4).

Table 3 The Regression Model

\begin{tabular}{|c|c|c|c|c|c|c|}
\hline \multicolumn{2}{|c|}{ Model } & \multirow{2}{*}{$\frac{\text { Sum of Squares }}{379,747}$} & \multirow{2}{*}{ Df } & \multirow{2}{*}{$\frac{\text { Mean Square }}{54,250}$} & \multirow{2}{*}{$\frac{\mathbf{F}}{3,429}$} & \multirow{2}{*}{$\frac{\text { Sig. }}{0,002}$} \\
\hline 1 & Regression & & & & & \\
\hline & Residual & 4508,925 & 285 & 15,821 & & \\
\hline & Total & 4888,672 & 292 & & & \\
\hline
\end{tabular}


In Table 3, the significant F-value of the ANOVA analysis reiterate that the model $(\mathrm{Y}=15,3+$ $0,21 x+0,19 x+0,15 x+0,13 x-0,05 x+0,04 x-0,01 x)$ fits the data very well. It means the overall explanatory state of the model was powerful. Hence, the result obtained on the basis of this regression model could steadily be regarded as dependable.

Table 4 The Regression Coefficient

\begin{tabular}{|c|c|c|c|c|c|c|}
\hline \multirow{2}{*}{\multicolumn{2}{|c|}{ Model }} & \multicolumn{2}{|c|}{$\begin{array}{l}\text { Unstandardized } \\
\text { Coefficients }\end{array}$} & \multirow{2}{*}{$\begin{array}{c}\begin{array}{c}\text { Standardized } \\
\text { Coefficients }\end{array} \\
\text { Beta }\end{array}$} & \multirow[t]{2}{*}{$\mathbf{T}$} & \multirow[t]{2}{*}{ Sig. } \\
\hline & & B & Std. Error & & & \\
\hline \multirow[t]{8}{*}{1} & (Constant) & 15,271 & 3,352 & & 4,555 & 0,000 \\
\hline & Content Relevance & 0,176 & 0,350 & 0,036 & 0,501 & 0,617 \\
\hline & Methods of Teaching & 2,557 & 0,423 & 0,210 & 1,315 & 0,001 \\
\hline & Assessment learning & 3,149 & 1,121 & 0,199 & 2,810 & 0,005 \\
\hline & Sex & $-0,125$ & 0,516 & $-0,014$ & $-0,242$ & 0,809 \\
\hline & Age & $-0,022$ & 0,027 & $-0,057$ & $-0,844$ & 0,399 \\
\hline & Marital status & 1,673 & 0,801 & 0,131 & 2,088 & 0,038 \\
\hline & Locality & 1,697 & 0,656 & 0,153 & 2,588 & 0,010 \\
\hline
\end{tabular}

a. Dependent Variable: Overall Outcome of AEL

Following the formation of the regression model, the result designates that the overall adult learning condition was affected significantly by variables, methods and assessment of learning, marital status and locality of learning situation. It is fact, when the adult education curriculum is relevant to the life of adults, their interest and overall achievement in retaining and translation knowledgeto their life is sustainable. In this regard, Courtney (1989) coined that the learning process must take into account on how an adult perceives and what is being taught. It includes, but is not limited to considering their previous learning experiences and their temporal perspective - especially when it comes to short term application of what is being taught, and matching education to their problems, needs, interests and expectations.

The findings of this study assured that the overall outcome of the adult education program is highly affected by the way and the method of assessment employed by adult education facilitators. According to Jones (2005), successful assessment for learning strategies result in improved learner progress on a continual basis. The principal characteristic of assessment for learning is effective feedback provided by moderators to learners on their progress. The value of the feedback is dependent on two factors, the quality of the feedback, and how learners receive and ultimately use it. These are important points for effective learning.

Research in the area of adult education emphasized that the learning result of adult learners can also be determined by the methodological approaches employed by facilitators and the way the learning achievement assessed by those who in one way or another involved in adult teaching learning process. Galbraith (2004) emphasized that being part of an effective educator involves understanding how adults learn best. Andragogy is a theory that holds a set of assumptions about how adults learn. Andragogy emphasizes to value the process and methods of learning. It uses approaches to learning that are problem-based and collaborative rather than didactic, the emphasis more on equality between the teacher and learner.

Collaborative learning as an element of andragogy has effects on the outcome of adult learning. A number of meta-analyses support the premise that collaboration "works" for promoting a broad range of student learning outcomes. In particular, collaboration enhances academic achievement, learners' attitudes, and retention (Prince, 2004). 
One expert in adult education sector of the Harari region, Ethiopia suggested that the perception of facilitators in the enactment of adult education program affect the learning outcome positively or negatively. In the current situation, it is difficult to conclude that facilitators have clear and appropriate perceptions on the boarder aim of adult education program. A dequate training should be arranged to facilitators on the mission and operation of the program: content, teaching methods and assessment of learning outcome.

According to Davis (2005) adult learning method includes procedures for creating a relaxed emotional state, an orchestrated and multi-sensory learning environment, and active learner engagement in the learning process. A relaxed emotional state includes relaxation and breathing exercises, suggestions, and a positive learning atmosphere. An orchestrated environment includes imagery, dramatic readings, instructional videos, and peripherals (posters and visual displays).

Table 4 reveals that adult education outcome is affected by the locality of the learners (his/her learning environment). This means that learning in rural areas is far behind than learning in the urban settings. This is for obvious reason that provisions of facilities are expected to be better in urban areas than in rural areas. This could happen owing to the nature of urban center sequipped with resources (human and material) than rural centers. As a result, it is believed that the availably of such centers with the required resources may contribute much to the development of positive attitudes and achievement of learning outcome in the adult education program (Lee, 2001).

In the findings, as revealed in Table 4, the marital status of the learners was one of the factors to determine the overall outcome of the current adult education program (Oumer, 2007). Researches show that delayed marriage increases educational attainment and academic test scores, while surprisingly a range of other adult outcomes such as self-reported health and wellbeing, migration decisions, asset ownership, political participation, attitudes and beliefs are unaffected (Ikamari, 2005).

Along with the above findings, an interview with one facilitators of the West Hararghe zone, Ethiopia was also conducted. As how it is suggested that adult learners have experienced enormous problems that disallow them not to efficaciously take part in the program. Among the most vibrant one are economic problems and the amount of members that a given family could have. When adults have multiple responsibilities at home, obviously they cannot be attentive in learning. This situation makes them to lag behind in their achievement of the learning outcomes. Accordingly, their experience in adult education program is in consequent to their life compared to their colleagues.

The above extract could be evidence for some of the factors that debilitate adult learning which are linked to the status of the respondents in terms of marriage (and corresponding family size) and the status of economy of the learner.

\section{CONCLUSIONS}

The findings of this research disclosed that the outcome of the adult education program is highly affected by the way adult education is deliberated and the method of assessment employed by adult education moderators. More importantly, the learning outcome of adult learner is determined by the methodological approaches employed by facilitators, who in one way or another plays pivotal role in adult teaching learning process. This would lead us to the conclusions that the methods and assessment procedures employed by adult facilitators have momentous contribution towards the attainment of the adult education program. 
Similarly, the research reveals that adult education outcome is affected by locality of the learners (his/her learning environment). This means that the experience the learner had in rural areas is far behind then learning condition in urban settings. In this regard, researchers also agreed that the geographical location of an institution, whether urban, suburban, small town, or rural, is expected to have marvelous impact on success due to the differences in organizational and social environments and the resources available. Although the patterns are not clear, the educational inequities in urban area suggest that large achievement gaps could exist between participants in these institutions and their peers in suburban and rural institutions (Everson \& Millsap, 2004). Thus, it is suggested to narrow this gap through recompensing special attention to learning in the rural settings.

An important implication of this study is adults'opportunities to repeat tasks or to have ideas repeated to reinforcelearning and skills. Practice is important in their learning, but should not consist of tediousdrills. In this sense, it is suggested to provide reinforcement by incorporating the same information or skills in a different ways through a variety of activities. To put this into effect, education bureaus, Ministry of Education and training institutions should work together to encourage the training of moderators on learning teaching styles and other assessment techniques as part of continuous professional development itinerary.

Last but not least, identifying these practices may assist in finding ways to further encourage and support adult learner to perform well. The current research shed light on important factors that impact adult learner achievement. Further research needs to be conducted to understand this phenomenon by including other factors like the learning facilities, instructional quality, and moderator- learner communication.

\section{REFERENCES}

Best, J. W., \& Khan, J. V. (2005). Research in Education. New Delhi: Pearson.

Davis, N. (2005). Just in Time Support for Educational Leadership. IFIP International Federation for Information Processing: Education and the Knowledge Society, 161, 271-277. doi:10.1007/0-387-23120-X_29

Everson, H. T., \& Millsap, R. E. (2004). Beyond Individual Differences: Exploring School Effects on SAT Scores. Educational Psychologist, 39(3), 157-172.

Galbraith, M. W. (2004). Adult Learning Methods: A Guide for Effective Instruction ( $3^{\text {rd }}$ Ed). Malabar: Krieger Publishing Company.

Gay, L. R., \& Airasian, P. W. (2003). Educational Research: Competencies for Analysis and Application (6 ${ }^{\text {th }}$ Edition). New Jersey: Prentice Hall.

Ikamari, L. D. E. (2005). The effect of education on the timing of marriage in Kenya. Demographic Research, 12(1), 1-28.doi:10.4054/DemRes.2005.12.1

Indabawa, S. A., \& Mpofu, S. (2006). The Social Context of Adult Learning in Africa. Hamburg: UNESCO Institute for Education.

Jones, C. A. (2005). Assessment for learning. London: Learning and Skills Development Agency. 
Kala, D., \& Chaubey, D. S. (2015). Attitude of Faculty Members towards Faculty Development Programs and their Perceived Outcomes. Pacific Business Review International, 8(2), 21-30.

Kanukisya, B. (2008). Contemporary Adult Education Policies and Practices in Tanzania: Are They Meeting National Challenges? (Master's thesis). Available from Repository of University of Oslo.

Lee, J. (2001). Interstate Variations in Rural Student Achievement and Schooling Conditions. ERIC Digest. Retrieved from http://www.ericdigests.org/2002-3/interstate.htm

Merriam, S. B., \& Brockett, R. G. (2007). The Profession and Practice of Adult Education: An Introduction. San Francisco: Jossey-Bass.

Merriam, S. B, \& Cunningham, P. M. (1989). Handbook of Adult and Continuing Education. San Francisco: Jossey-Bass.

Ministry of Education. (2005). Education Sector Development Program (ESDP III): Program Action Plan. Addis Ababa: Ministry of Education.

Ministry of Education. (2008a). National Adult Education Strategy. Addis Ababa, Ethiopia.

Ministry of Education (2008b). National Report on the Development and State of the Art of Adult Learning and Education (ALE). Addis Ababa, Ethiopia.

Ministry of Education. (2010). Education Sector Development Program (ESDP IV): Program Action Plan. Addis Ababa: Ministry of Education.

Ministry of Education. (2011a). Integrated Functional Adult Literacy Curriculum Framework. Addis Ababa: Ministry of Education

Ministry of Education. (2011b). Functional Adult Literacy Implementation Guideline. Addis Ababa: Ministry of Education.

Nafukho, F. M., Wawire, N. H W., \& Lam P. M. K. (2011). Management of Adult Education Organization in Africa. Hamburg: UNESCO Institute for Education.

Oumer, J. (2007). The challenges of free primary education in Ethiopia. Paris: International Institute for Education Planning.

Prince, M. (2004). Does Active Learning Work? A Review of Research. Journal of Engineering Education, 93(3), 223-231.

Sarantakos, S. (2005). Social Research. New York: Palgrave Macmillan.

Tight, M (1996). Key Concepts in Adult Education and Training (Routledge Key Guides). London: Routledge.

Tilak, J. B. G. (2006). The Role of Post-Basic Education in Alleviation of Poverty and Development. Edinburgh: University of Edinburgh.

Torres, R-M. (2003). Lifelong Learning: A new momentum and a new opportunity for Adult Basic Learning and Education (ABLE) in the South. Stockholm: Swedish International Development Corporation Agency. 
UNESCO. (2007). Education for All Global Monitoring Report 2008: Education for All by 2015: Will We Make It? Paris: UNESCO.

UNESCO. (2010). World Heritage and Cultural Diversity. Germany: German Commission for UNESCO. 